NBER WORKING PAPER SERIES

\title{
THE EFFECT OF SCHOOL CHOICE ON INTRINSIC MOTIVATION AND ACADEMIC OUTCOMES
}

\author{
Justine S. Hastings \\ Christopher A. Neilson \\ Seth D. Zimmerman \\ Working Paper 18324 \\ http://www.nber.org/papers/w18324
NATIONAL BUREAU OF ECONOMIC RESEARCH
1050 Massachusetts Avenue
Cambridge, MA 02138
August 2012

The authors would like to thank Brian Jacob and participants at the 2011 ASSA meetings for helpful comments. Sarah Johnston provided outstanding research assistance. Hastings thanks the Brown University Population Studies and Training Center and the Yale University Institution for Social and Policy Studies for support. The views expressed herein are those of the authors and do not necessarily reflect the views of the National Bureau of Economic Research.

NBER working papers are circulated for discussion and comment purposes. They have not been peerreviewed or been subject to the review by the NBER Board of Directors that accompanies official NBER publications.

(C) 2012 by Justine S. Hastings, Christopher A. Neilson, and Seth D. Zimmerman. All rights reserved. Short sections of text, not to exceed two paragraphs, may be quoted without explicit permission provided that full credit, including $(\odot)$ notice, is given to the source. 
The Effect of School Choice on Intrinsic Motivation and Academic Outcomes

Justine S. Hastings, Christopher A. Neilson, and Seth D. Zimmerman

NBER Working Paper No. 18324

August 2012

JEL No. I20,I21,I24

\begin{abstract}
$\underline{\text { ABSTRACT }}$
Using data on student outcomes and school choice lotteries from a low-income urban school district, we examine how school choice can affect student outcomes through increased motivation and personal effort as well as through improved school and peer inputs. First we use unique daily data on individual-level student absences and suspensions to show that lottery winners have significantly lower truancies after they learn about lottery outcomes but before they enroll in their new schools. The effects are largest for male students entering high school, whose truancy rates decline by $21 \%$ in the months after winning the lottery. We then examine the impact attending a chosen school has on student test score outcomes. We find substantial test score gains from attending a charter school and some evidence that choosing and attending a high value-added magnet school improves test scores as well. Our results contribute to current evidence that school choice programs can effectively raise test scores of participants. Our findings suggest that this may occur both through an immediate effect on student behavior and through the benefit of attending a higher-performing school.
\end{abstract}

Justine S. Hastings

Brown University

Department of Economics

64 Waterman Street

Providence, RI 02912

and NBER

justine_hastings@brown.edu

Christopher A. Neilson

Yale University

Department of Economics

37 Hillhouse Ave.

New Haven, CT 06511

christopher.neilson@yale.edu
Seth D. Zimmerman

Yale University

Department of Economics

37 Hillhouse Ave.

New Haven, CT 06511

seth.zimmerman@yale.edu 


\section{Introduction}

The federal No Child Left Behind Act (NCLB) of 2001 set out to reform public education by introducing accountability measures coupled with a public school choice requirement for all schools receiving federal Title I funds (Title I schools). The public school choice component requires that districts allow parents of children at persistently under-performing schools the option to send their child to a higher-performing school. Such school choice and accountability programs are intended to provide all students the opportunity to obtain a high-quality education.

This paper examines whether and how school choice and accountability systems accomplish these goals. Using data on student outcomes and school choice lotteries from a lowincome urban school district, we consider two mechanisms through which school choice may improve student outcomes. First, school choice may raise intrinsic motivation for students who are offered the opportunity to attend a high-quality school. Second, students who choose to attend high-quality schools may benefit from improved school and peer inputs.

To evaluate the role these two mechanisms plays in improving student outcomes, we look at changes in test scores, absences, and suspensions for winners and losers of school choice lotteries. We measure the effects of changes in intrinsic motivation separately from the effects of changes in school inputs by estimating the impact winning the lottery has on absences and suspensions after students learn about lottery outcomes but before they enroll in their new schools. We use unique daily data on student absences and suspensions to address the question of whether student behavior responds positively to the opportunity to attend a better school even before that opportunity is realized. We then measure the impact of attending a chosen school on student test scores using lottery assignments as an instrument for chosen school attendance. This impact reflects a combination of changes in student effort and gains in school quality.

We find that the opportunity to attend a better school has positive and significant effects on both student attendance and test scores. After students are notified of lottery outcomes, truancy rates for choice lottery winners fall relative to those for lottery losers, whose truancy rates do not change relative to lottery non-entrants with similar observable characteristics. The effects are largest for male students entering high school, whose truancy rates decline by $21 \%$ as a result of winning the lottery. This suggests that the opportunity to attend a first choice school improves intrinsic motivation for students even before they arrive at their new school. 
Once lottery winners attend their chosen schools, we find sizable gains in test scores relative to those who lost the choice lottery. Students who attend first choice schools realize average test score gains (across all subjects) of 0.19 student-level standard deviations. Test score effects are heterogeneous across the type of first choice school, with students who chose a high achieving "No Excuses” charter school experiencing large gains in combined test scores of over three-tenths of a student-level standard deviation. These gains are concentrated in reading and writing. Students who chose public magnet schools experience gains in both reading and math, but the point estimates are smaller and marginally-significant-to-insignificant across specifications. We find that score gains for magnet school lottery winners are generally consistent with predictions based on OLS estimates of magnet and default school quality: differences in value added measures by score subject between magnet choice and home school predict the change in test score for lottery winners (Deming et al. 2011). However, lotteries for charter schools do not conform to these predictions. One explanation for this finding is that selection into specialized charter schools is more strongly correlated with unobservable determinants of academic success in areas the charter may specialize in, as opposed to selection into magnet programs, which in many cases follow similar curricula to non-magnet public schools.

Our results build on a growing literature that exploits the random assignment of children to schools to evaluate the effects of charter and magnet attendance on test scores (Cullen, Jacob, and Levitt 2006; Cullen and Jacob 2008; Hastings, Kane, and Staiger (2006, 2008); Hastings and Weinstein 2008; Hoxby and Murarka 2009; Angrist et al 2011; Deming et al 2011). In the context of this literature, our estimates of the effects of lottery outcomes on same-year absence rates are (to our knowledge) the first analysis to examine the potential for an individual's own intrinsic motivation to increase achievement as a result of school choice. Our findings indicate that changes in student effort may drive at least part of the effects observed in previous studies. This is consistent with increasingly convincing evidence on the importance of non-cognitive skills in determining academic outcomes (see, e.g., Heckman, Stixrud, and Urzua 2006). In addition, we find that students' test scores benefit substantially from attending first choice schools. This adds to evidence that school choice programs can effectively raise test scores of those participating both by the intrinsic effect offering choice has on student motivation and effort and through the benefit of attending a higher-performing school. 


\section{Background}

\section{Public School District Description}

Our analysis focuses on public and charter schools in a mid-sized urban school district which we will refer to as "the district." ${ }^{11}$ As in many urban areas, the district primarily serves minority and low-income children. It has an enrollment of approximately 20,000 students, of whom more than $80 \%$ are eligible for free lunch, $12 \%$ are English language learners and approximately $90 \%$ are either black or Hispanic.

Students in the district participate in standardized tests each year, which vary depending on grade level. The State Mastery Test (MT) is taken at the end of grades three through eight and has separate reading, writing, and math. The State Academic Performance Test (APT) test is administered in grade ten and also covers mathematics, reading, writing, and science. ${ }^{2}$ Students receive separate APT scores for each subject, and students who fail a subject are required to retake it the following year. Performance on these standardized tests is part of the State's achievement evaluation system under No Child Left Behind (NCLB).

Starting in the early 1990s, the district undertook a series of educational reforms that resulted in the current district-wide magnet school and charter school choice program. ${ }^{3}$ In 2002 and 2007, the district received one of roughly a dozen five-year grants provided under the voluntary school choice program (VSCP) provision of NCLB. ${ }^{4}$ The VSCP supports projects that "offer the widest variety of choices to students in participating schools, including options that allow students to transfer from low-performing schools to higher-performing schools.” District students can choose from a large menu of schooling options. Currently, half of the schools in the district (20) are magnet schools, and over a third of the students in the district $(7,000)$ apply to them each year through a centralized lottery system. Of nine district high schools, eight are magnet schools open to choice, implying that almost all high school students either participate in school choice themselves or attend school with students who did.

\footnotetext{
${ }^{1}$ While the district supported this project, they requested we not disclose their name in this working paper.

${ }^{2}$ For a number of our student cohorts, the APT and MT science tests were administered in a more limited subset of grades than were the other tests. We therefore exclude the science tests from our analysis.

${ }^{3}$ This school choice program satisfies the NLCB choice requirement that students attending Title I Improving schools be given the option to attend another non-failing school in the district. The school choice program has been cited as a model for other districts nationwide implementing Title I Choice programs under NCLB.

${ }^{4}$ A Department of Education press release describing the program and program recipients is available at http://www2.ed.gov/news/pressreleases/2007/07/07272007.html. Accessed July 15 ${ }^{\text {th }}, 2012$.
} 
In addition to the magnet schools, charter schools run by a prominent charter school chain have operated in the district since 1998. The first charter opened in 1998, serving elementary and middle school students. The charter has since expanded to include two elementary schools, two middle schools, and one high school. This charter school chain follows the "No Excuses" school model, which aims to improve outcomes for urban students from disadvantaged backgrounds through long school days, long school years, a rigorous teacher evaluation process, and an emphasis on parental involvement. "No Excuses" schools are frequently cited as examples of successful urban charter schools, ${ }^{5}$ and they serve a large and growing body of urban students. Table 1 displays a breakdown of student characteristics within each school type pooled across the academic years 2005-2006 through 2008-2009.

\section{The School Choice Lottery Process}

Students are admitted to charter and magnet schools via lottery. Lotteries take place once each year, typically in March. Students submit an ordered list of up to three schools to the district, which then conducts a first-choice maximizing lottery. The lotteries proceed as follows. First, students are grouped by first choice school, grade, and, if applicable, preference category (some schools give preference to students who live within a certain neighborhood-walk-zone or have siblings who already attend the school). ${ }^{6}$ Within each group, students are assigned a ranking by lottery number. Admissions are processed for priority lotteries first, and then non-priority lotteries if space permits. If open spots remain after the first choice round is complete, unplaced students are grouped according to their second choice (and priority group where applicable), and the process repeats.

Table 2 shows the characteristics of the students who participate in the school choice lottery by grade level. Students are most likely to participate in lotteries in transitional grades; these are students entering school between pre-kindergarten and first grade, fifth and sixth graders entering middle school, and ninth graders entering high school. Overall, lottery participants are more likely to be black, less likely to be Hispanic, and less likely receive free lunch than non-participants. Table 2 also compares test scores for students applying to lotteries in the year they apply versus their counterparts who do not apply. We standardize the test scores

\footnotetext{
${ }^{5}$ See, e.g., Angrist et al. 2011.

6 The majority of district magnet schools accept out-of-district students in addition to in-district students. These schools run separate lotteries for in- and out-of-district students.
} 
to the state-wide mean and standard deviation by grade level. In general, students exercising choice are higher scoring than their non-choice counterparts, particularly entering grade nine.

In practice, the first-choice maximization procedure results in most students either receiving their first choice or not being placed in any of their selected schools. ${ }^{7}$ We define lotteries by priority, grade, and first choice school. Within this triplet, lottery number alone should determine admission and the lottery number should be orthogonal to baseline student characteristics. Of the 16,107 students over our 4 years of data who submitted school choice applications for charter and magnet schools, 8,404 of them were in lotteries with at least ten students and for whom some students were admitted and others were declined admission. We will focus our analysis on these marginal lottery groups, because it is within these groups that randomly assigned lottery numbers impact students’ attendance options.

\section{Using Lottery Outcomes as Exogenous Variation}

\section{Estimation framework}

Our goal is to examine how school choice affects student effort and academic performance. We measure changes in effort using measures of attendance and behavior in the spring semester after lottery outcomes are announced but before students attend their newly chosen school. This allows us to separate effects of lottery outcome on behavior from the effects of policies in place at the chosen school. We measure the effect of attending the chosen school using test score outcomes from the end of the first school year after lottery outcomes are announced (the first year of lottery school attendance for complying lottery winners).

To estimate these effects, we need variation in admission to and attendance at first choice schools that is orthogonal to the outcomes of interest conditional on observables. Following the literature, we use lottery numbers conditional on lottery dummies to generate the needed exogenous variation in admission to and attendance at first choice schools. This identification strategy requires that lottery numbers be randomly assigned and that they strongly predict admission to and attendance at chosen schools. We start by verifying that these two properties hold in the district's school choice lotteries.

\footnotetext{
${ }^{7}$ Overall, 51.7 percent of students were placed in their first choice school, 32.0 percent of students were waitlisted, and 12.3 percent placed in their second or third choice school. The remaining 4 percent of students left the lottery process and did not receive a placement.
} 


\section{Constructing Sample and Lottery Instrument}

The lottery and assignment files include students' choices, their priority group for each choice (i.e., data on whether they have a sibling in a listed school or live in its zoned neighborhood), an indicator for whether they are applying from within or outside the district, their lottery number, and the school to which they are assigned. The choice lists, priority indicators, and in-district indicators allow us to identify groups of students competing for admissions spots, and the lottery numbers allow us to create admission ranks within these groups. However, the school assignment variables are the product of an assignment process that begins with the lottery and ends after the start of the next school year when classroom rosters are finalized. Between lottery notification in the early spring and the beginning of the next school year the following fall, some initially rejected students are pulled in off of a waitlist as lottery winners decline their positions or students already enrolled in the target school choose to leave.

Final school assignments thus reflect families' endogenous responses (e.g., families that were easiest to reach when called for a newly open spot), and endogenous errors in forecasts of school principals as to how many choice spots they would have in the fall (if more students than expected are retained, more slots open up). Therefore, rather than using reported lottery assignments to instrument for school attendance, we construct a simulated lottery outcome variable using records on the number of seats available within each lottery block at the time of the lottery. If a student entered a lottery in which $g$ seats were available, and had one of the best $g$ numbers in that lottery, then we code that student as having won the simulated lottery.

We will use the simulated lottery outcome to generate exogenous variation in school attendance and focus our analysis on school choices for which winning the lottery is a strong determinant of final admission. For many small lotteries, where only a handful of seats are available, there is little correlation between lottery number and final admissions assignment. We exclude lotteries for which the estimated coefficient in a univariate regression of final first choice assignment on simulated lottery outcome is less than 0.2 . Our results are generally insensitive to changing this cutoff value, though reducing it weakens the relationship between lottery results and school assignment, and raises our standard errors. Appendix A describes in detail the construction of our lottery winning indicator, its correlation with final admission, and the lotteries that are included versus excluded from our final sample. 
We arrive at our final sample as follows. We start with a total of 16,107 lottery participants across all charter and magnet school choices over 4 years. We first drop any observations for students who participate in a lottery (defined by priority, grade level, and school choice for each school year) which has fewer than ten students or a lottery for which all students are admitted or all students are waitlisted. This leaves us with 8,404 observations. We next drop the 247 observations without a normal grade progression, reducing our sample to 8,157 observations. Finally, we drop observations where the first choice school is a "transitional" magnet school targeting at risk students with special needs (25 observations), the district's smallest charter school (21 observations), or a magnet in another district (248 observations). This leaves us with 7,863 observations in what we term the marginal lottery sample. We then impose the regression-based cutoff for the correlation between lottery number and admission by the start of the school year. This reduces our sample size further to 4,277. We observe outcome year math, reading, and writing scores for 1,799 of these students. This group makes up the sample used in our test score analysis. We analyze subsets of students for whom baseline scores and school zone information are available when necessary. To construct the sample used for our truancy analysis, we take the marginal lottery sample and link it to absence and suspension records from the year in which the lottery took place. Records are available for 4,293 students. We do not impose the regression-based cutoff in our truancy sample because a) students may benefit from motivational effects at the time of notification even when lotteries turn out be nonbinding ex post, and b) a strong first stage effect of lottery outcome on first choice attendance is not required for this component of the analysis.

Table 3 tests the balance of baseline characteristics across simulated lottery outcomes for the full sample and for samples used in the test score analysis. ${ }^{8}$ The table gives point estimates and standard errors for $\theta$, from regressions of the form

$$
X_{i}=\alpha+\theta Z_{i}+T_{i}^{\prime} \gamma+\varepsilon_{i}
$$

where $X_{i}$ is the predetermined baseline characteristic labeled in each row of the table, $Z_{i}$ is the simulated lottery outcome, and $T_{i}$ is a vector of lottery dummies. Our lottery outcomes should

\footnotetext{
${ }^{8}$ As we discuss below, truancy specifications are based on within-individual changes before and after lottery notification and do not rely on lottery balance. We therefore focus on the test score sample here.
} 
not predict predetermined characteristics. We show these regression estimates for four basic samples. The first sample is all students in marginal lotteries (i.e., that lotteries that contained both losers and winners). The second sample examines only students in the standardized test taking grades, three to ten, and the third sample adds the further restriction that students have baseline test scores to examine the impact of winning the lottery on baseline test score. Columns 2 and 3 demonstrate balance in baseline characteristics for students in lotteries used in the analysis of outcome year scores. The restriction that students must have baseline scores reduces the sample size by $42 \%$, as many students applying to district magnets are either too young to have test scores or are coming from nearby suburban districts through regional school choice programs, and therefore do not have baseline test scores within the district data. ${ }^{9}$

Out of 15 total balance specifications, none are significant at the five percent level. Pvalues from F-tests of the null hypothesis that the coefficients on all baseline variables are jointly equal to zero are reported in the last row of Table 3. We fail to reject the null at the ten percent level in any joint specification, and view this as being consistent with our null hypothesis that simulated lottery outcomes are exogenous. We now examine the impact of winning the lottery on measures on student effort and student achievement.

\section{Results}

\section{Effect of Winning a Lottery on Student Effort}

We begin by using daily student-level data on absences and suspensions to examine the impact of winning admission to a chosen school on student effort. Our goal is to determine whether winning (losing) admission to a chosen school encourages (discourages) students enough to generate a significant measurable change in truancy. To estimate the impact of lottery notification on student absences and suspensions, we estimate regressions of the following form:

$$
Y_{i y t}=\alpha_{i y}+\text { ppost }_{t}+\theta p o s t_{t} * \text { won_lottery }_{i}+\varepsilon_{i y t}
$$

which can be written in first differences as

$$
\Delta Y_{i y}=\beta+\theta w o n_{-} \text {lottery }_{i}+v_{i y}
$$

\footnotetext{
${ }^{9}$ Attempts to access state-level score data are ongoing.
} 
where $Y_{i y t}$ is truancy rate (defined here as the average weekly number of absences and suspensions) for student $i$ in period $t$ of school year $y$. The indicator, post $t_{t}$, takes the value of 1 for $t$ after lottery notification, and our variable of interest, post $_{\mathrm{t}}{ }^{*}$ won_lottery $_{i}$, is an interaction between winning the lottery and post. We aggregate our daily data into a two-period model and take first differences within student to avoid potential bias in our standard errors due to autocorrelation in truancies (Bertrand, Duflo, and Mullainathan, 2004). Our coefficient of interest, $\theta$, captures post-lottery change in the truancy rate for lottery winners relative to lottery losers.

Table 4 presents the difference-in-difference estimates for all students and within gender and age groups. We disaggregate by these characteristics because they play an important role in determining truancy rates. The first three columns present results pooled across genders for all grades, grades 4 and above, and grades 7 and above. The results show negative and significant impacts of winning the lottery on truancies of approximately $7 \%(-0.02 / 0.27)$, implying that lottery winners have 7\% lower truancies than lottery losers post-lottery notification. Notice that the mean difference post vs. pre lottery is positive - overall truancies rise in the latter part of the school year, but rise less for those winning the lottery. The next six columns show the same results for males (columns 4-6) and females (columns 7-9). Almost all of the full-sample effect is coming from males, who experience a $14-21 \%$ decline in truancies as a result of winning the lotteries. The lower effect of $14 \%(-0.038 / 0.272)$ is observed in the pooled grade sample; when we focus on older students, the impact increases to $21 \%$. This is not surprising as overall truancies rise with age among males, and older children have more autonomy when it comes to choosing whether to attend school and how to behave while there.

These results suggest that particularly among males, intrinsic motivation may be an important aspect of school choice's impact on academic achievement. However, it is unclear if winning the lottery to attend a chosen school decreases truancies by offering positive motivation (hope), or if it increases truancies among lottery losers through negative motivation (discouragement). To make this important distinction, we compare changes in truancy rates after lottery notification for both winners and losers to changes in truancy rates for lottery nonparticipants. When conducting this comparison, we use a propensity score approach to better match the baseline characteristics of the students not participating in the lottery to those of 
lottery participants (Hirano et al., 2003; Barsky et al., 2002; Imbens, 2004; Hastings et al. 2007). Let the propensity score, $\hat{p}$, be the probability that a student applies to a lottery as a function of baseline characteristics. We reweight observations outside of our lottery sample by $\frac{\hat{p}}{1-\hat{p}}$, which balances the distribution of baseline characteristics between the lottery and non-lottery samples. To construct the propensity score, we estimate a separate probit for each grade and school year, controlling for home school fixed effects, demographics, and pre-notification truancies.

Table 5 presents the results. The first row is the mean change in truancies for lottery losers while the second row is the mean change in truancies for lottery winners, both measured relative to the change in truancies in the non-lottery group. The results suggest that the impact on truancies is coming primarily from a decrease in truancies among lottery winners (the positive motivation effect). For the pooled gender results in columns 1-3 and the subgroup results for males in columns 4-6, the coefficient on lottery winning is negative and significant and very close in magnitude to the results presented in Table 4. The coefficients on lottery losing are negative, but close to zero and insignificant. Tests of equality of the coefficients on lottery winning and losing reject the hypothesis that the effects are equal at the $5 \%$ level or higher. Among girls, there is no significant impact on lottery winners or losers relative to each other or to the control group.

These results are consistent with the hypothesis that school choice benefits students by raising levels of intrinsic motivation. Being offered a slot at a chosen school appears to cause male students in particular to put more effort into school attendance after lottery notification, implying that some of the academic benefits of school choice accrue even before students attend the chosen school. ${ }^{10}$ This motivational impact may spill over into the subsequent year's academic achievement. We now measure the impact of choice on standardized test score performance.

\section{Effect of Attending a Chosen School on Academic Achievement}

We first conduct a lottery-based evaluation of test score gains for students whose school choices are determined by lottery outcomes. Following the literature, we estimate the following equations using our simulated lottery outcome as an instrument for attending a first choice school.

\footnotetext{
${ }^{10}$ This result may be conceptually connected to the medical literature on placebo effects; the mental impact of treatment can have a significant and sometimes equal impact to actual treatment.
} 


$$
\begin{aligned}
& Y_{i}=\gamma D_{i}+X_{i}^{\prime} \beta+\varepsilon_{i}, \\
& D_{i}=\alpha Z_{i}+X_{i}^{\prime} \theta+e_{i},
\end{aligned}
$$

where $Y_{i}$ is student test score, $D_{i}$ is a dummy variable equal to one if student $i$ attends their target school and zero otherwise, $X_{i}$ is a k-vector of observable and predetermined student characteristics, and $\varepsilon_{i}$ is a mean-zero error term. We use an indicator for winning the lottery, $Z_{i}$, to attend a chosen school as an instrument for attending a chosen school. We will also present the reduced-form Intent-to-Treat (ITT) effects, substituting $Z_{i}$ for $D_{i}$ in equation (3).

Table 6 reports estimates of the effects of lottery outcomes on first choice attendance, sample attrition, and outcome-year test scores. Because many students lack baseline test scores, we present the results for all students who have outcome test scores (column 1) as well as for those with both outcome and baseline test scores (column 2). Specifications in the first column do not include any controls, while specifications in the second column control for baseline test scores.

The first panel of Table 6 presents first stage results within the sample of students for whom outcome test scores are available. For these students, winning the simulated lottery raises the probability of first choice attendance by 59 percentage points. For the subgroup of students with available baseline test scores, the first stage estimate is 61 percentage points. The strength of our first stage estimates suggests that our simulated lottery outcome closely approximates actual lottery results.

The second and third panels address the relationship between lottery outcome sample attrition within the sample of lotteries where at least some students have outcome test scores. The dependent variable in the second panel is an indicator variable equal to one if a student is not enrolled in a district school in the test score outcome year. Students who win the lottery are 9.2 percentage points less likely to exit (or, in the case of out-of-district students, not to enter) the district. This represents more than three quarters of the mean attrition rate of 12 percent. The dependent variable in the third panel is an indicator variable equal to one if we do not observe test scores in all subjects in the outcome year. Lottery losers are 14.4 percentage points more likely than lottery winners to have missing outcome year test scores. 
Column two presents specifications in which we regress the relevant measure of attrition on lottery outcome, baseline combined score, and the interaction between lottery outcome and baseline combined score. The magnitudes of the main effect estimates are similar to those reported in the first column. Students with higher baseline scores are no more likely to leave the district than other students, but are substantially less likely to have missing outcome year score data. The estimated coefficients on the interactions between baseline score and the attrition measures are close to zero and statistically insignificant. There is thus no evidence that the attrition differential between winners and losers is related to test score. For our analysis of test score effects, we use outcome-year observations for which all scores are observed. We discuss the impact of attrition on our estimates of test score effects in more detail below.

The fourth panel shows the impact of winning the simulated lottery on test score outcomes. On average, winning the lottery raises combined test scores (the average of reading, writing, and math scores) by 0.111 student-level standard deviations. The combined score effect is significant at the one percent level. Controlling for baseline scores in the sample of students for whom these scores are available raises the estimated effect size to $0.161 .{ }^{11}$ We then split our sample by magnet and charter schools. Winning the lottery to attend a charter school raises combined test scores by a statistically significant 0.260 standard deviations in the full sample, and 0.244 standard deviations among the sample with baseline test scores. Magnet schools have no significant positive impact on test scores in the full sample, however when we control for baseline test scores, winning a lottery to attend a magnet school increases combined test scores by 0.124 student-level standard deviations - significant at the one percent level, and about half of the effect of winning the lottery to attend the charter school.

To address the impact that differential attrition could have on our estimates, we compute non-parametric bounds following Lee (2009). Under the assumption that censoring is monotonic (i.e., students observed if they lose the lottery would also have been observed if they had won), these bounds capture the range of possible effects for students who do not attrit. ${ }^{12}$ As show in Table B1, these bounds are generally quite wide due to large differential attrition and large variation in outcome test scores. In the full sample, the point estimate of the lottery effect is

\footnotetext{
${ }^{11}$ The increase in estimated effects appear to be driven largely by the sample change; including additional demographic controls in the column one specification does not meaningfully affect our estimates.

${ }^{12}$ We compute Lee bounds separately within each lottery and take the entrant-weighted average upper- and lowerbound effects over all lotteries. 14 percent of students enrolled in lotteries where winners had higher attrition rates than losers; in these lotteries we assumed that attrition was exogenous.
} 
0.111, with an upper bound of 0.316 and a lower bound of -0.094 . In the subsample with baseline test scores, the point estimate is 0.160 with an upper and lower bound of 0.280 and 0.041 , respectively. For the magnet school lotteries, where attrition and outcome test score variance are larger, the lower bound, point estimate, and upper bound for the ITT effect are $(-0.173,0.063$, $0.295)$ and $(-0.014,0.132,0.269)$ for, respectively, the full sample and baseline-test-score sample. ${ }^{13}$ For the charter lotteries, the lower bound estimate is well above zero for both samples, suggesting that even in the worst-case attrition scenario charter lottery winners experience meaningful gains in test scores.

\section{Explaining heterogeneous effects}

A portion of the estimated gains from attending a chosen school may be attributable to increases in student effort or motivation that arise before students benefiting in any direct way from attendance at the first choice school. In addition, there may be heterogeneity in the effectiveness of various magnet schools, and magnets and charters may specialize in improving particular skills and may attract students and families with different characteristics and expectations. To further understand the factors driving the effects in Table 6, we disaggregate results by subject (reading, writing, and math).

Table 7 presents IV estimates of the effects of first choice school attendance on test scores by first choice school type and test subject, where we instrument for first choice school attendance with simulated lottery outcome. The first panel of Table 7 presents results for the full sample of lottery participants. First choice attendance has a small and statistically insignificant effect on math scores, but large and highly significant effects on reading, writing, and combined scores. First choice attendance raises reading scores by 0.24 standard deviations, writing scores by 0.30 standard deviations, and combined scores by 0.19 standard deviations.

The next two panels present results for magnet and charter school lottery entrants. The estimated effects are heterogeneous across school type. Magnet schools raise students' math scores by 0.16 standard deviations (significant at the ten percent level), while charters have a negative and statistically insignificant effect. Magnet schools raise students reading scores by 0.19 standard deviations (significant at the 5 percent level), compared to 0.35 standard deviations

\footnotetext{
${ }^{13}$ We are currently working with state officials to collect test score data for attrited students who move to other districts to hopefully tighten our estimates for magnet schools.
} 
(significant at the one percent level) for charter schools. Finally, magnet schools have little effect on writing scores, while charter schools raise writing scores by a strikingly large 0.79 standard deviations. Combined score gains for magnet school attendees are 0.12 standard deviations, compared to 0.35 standard deviations for charters.

Both magnets and charters appear to raise students' scores, but they have different mean impacts across the three subjects tested. The estimated impact of attending a chosen school may include gains that are attributable to school-level factors that affect all students in all subjects (i.e., school-level mean value added), gains that reflect school-level subject-specific productivity, and gains that reflect heterogeneity in the match quality between the student and the chosen school or school/subject combination. Heterogeneous student-school match effects may be particularly important in the context of schools with academic programs that are specialized in terms of subjects, learning methods, or learning environments. For instance, the charter school's use of a "No Excuses" model differentiates it from other district schools, and students may select into the charter based on its use of this model.

Let $Y_{i j}$ denote test scores for student $i$ if she attends school $j$.

$$
\begin{gathered}
Y_{i j}=X_{i}{ }^{\prime} \beta+\rho_{i} Q_{j}+\varphi_{i j}+\varepsilon_{i j} \\
Q_{j}=\delta_{j}+\vartheta_{j}
\end{gathered}
$$

Scores for student $i$ in school $j$ depend on her own observable characteristics $X_{i}$, a populationwide school academic quality measure, $Q_{j}$, student $i$ 's responsiveness to academic quality, $\rho_{i}$ (e.g., effort, preferences for achievement, or heterogeneous production, with a population mean of one (Hastings, Kane, and Staiger 2009)), a mean-zero school-student match effect $\varphi_{i j}$ that could be known to parents at the time of choice, and an idiosyncratic error term realized after the student attends the school, $\varepsilon_{i j}$. Academic quality $Q_{j}$ is equal to the sum of $\delta_{j}$, the estimated school effect from a regression of test scores on student observables and school dummies, and an error term $\vartheta_{j}$. Depending on whether students select into schools on the basis of unobservable test score determinants, the $\vartheta_{j}$ may or may not have zero mean. 
Let $j=1$ and $j=0$ denote the first choice and home school, respectively. Let $D_{i}=1$ if student $\mathrm{i}$ attends her chosen school and $D_{i}=0$ if she attends her home school. Observed test scores at the end of the first year can be written as

$$
Y_{i}=X_{i}^{\prime} \beta+\gamma_{i 0}+\rho_{i} D_{i} \Delta \delta+\theta_{i} D_{i}+\omega_{i}
$$

where $\Delta$ denotes the difference between the chosen and home school value of the corresponding variable, $\gamma_{i 0}=\rho_{i} \delta_{0}+\varphi_{i 0}$ and $\theta_{i}=\Delta \varphi_{i}$ are random coefficients, and $\omega_{i}=\Delta \varepsilon_{i} D_{i}+\varepsilon_{i 0}+$ $\rho_{i}\left(D_{i} \Delta \vartheta+\vartheta_{0}\right)$ is an error term. To estimate the mean $\rho$ and $\theta$ among students who choose a particular school, we use the simulated lottery numbers as an instrument for $D_{i}$, and its interaction with the difference in value added between the chosen and home schools as an instrument for $D_{i} \Delta \delta$. The estimation equation is

$$
Y_{i}=X_{i}^{\prime} \beta+\rho D_{i} \Delta \delta+\theta D_{i}+\Gamma_{l(i)}+\Lambda_{h(i)}+\omega_{i}
$$

where $\Gamma_{l(i)}$ is a lottery fixed-effect and $\Lambda_{h(i)}$ is a home school fixed effect. To recover the $\Delta \delta$, we first estimate an OLS regression of test scores on individual characteristics, a cubic function in baseline test score, and school dummies. The coefficients on the school dummies are the $\delta^{\prime}$ s. Schools in the district including the charters and magnets are sufficiently large that "shrinking" the value added measures using an Empirical Bayes approach did not substantially impact our value added estimates. We abstract from sampling error in the $\Delta \delta$ when estimating standard errors in our IV specifications.

Because lottery compliance is imperfect, we interpret our estimates $\hat{\theta}$ and $\hat{\rho}$ as local average treatment effects for students who comply with the lottery outcome. For these students, $\hat{\theta}$ is the mean score gain given a home school and lottery target school with equal value added estimates, while $\hat{\rho}$ is the score gain per unit of value added differential. If students selecting into schools through the lottery or through other admissions channels do so in a way that is uncorrelated with their unobservable heterogeneity terms, then $\hat{\theta}$ and $\hat{\rho}$ will converge in probability to their population averages of zero and one, respectively. Deviations of $\hat{\theta}$ and $\hat{\rho}$ from these values provide evidence of selection into schools that is correlated with student heterogeneity. Note that non-lottery-based selection that systemically biases the $\delta_{j}$ away from 
the $Q_{j}$ can produce evidence of selection into schools even if lottery-based selection is uncorrelated with student heterogeneity.

Table 8 summarizes $\delta_{0}, \delta_{1}$, and $\Delta \delta$ for students who chose first choice schools of different types. On average, charter and magnet lottery entrants choose target schools with combined-score value added estimates that are about 0.17 standard deviations above the value added estimates for their default zoned school. Notice that this is nearly identical to the 0.19 standard deviation combined score gain for students who attend their first choice school. The gap for charter lottery students is slightly higher at 0.18 , compared to 0.16 for magnet applicants. However, charter applicants typically have access to higher value added home schools: the average default school value added for charter applicants is -0.01 , compared to -0.19 for magnet applicants. Also, though average value added gaps are similar for charter and magnet applicants, the gaps for magnet applicants are much more variable. The standard deviation of the value added gap for magnet applicants is 0.10 , compared to 0.05 for charter applicants. Patterns in school value added are similar for math scores. Charter school applicants have a smaller value added gap than magnet applicants in reading score and a much larger gap in writing scores. However, magnet and charter applicants make good choices on average, in the sense that the large majority apply to schools better than their zoned school.

Table 9 presents instrumental variables regressions of the form described in equation (7) for math, reading, and writing scores. In the full sample, the coefficient on value added interacted with winning the lottery is significant and close to 1 for math and writing scores, and close to one but insignificant for reading. The impact of attending a chosen school for those with a choice and home school of equal mean "quality" is insignificant and close to zero, suggesting that on average selection on idiosyncratic match or ability to capitalize on increased school quality is not a primary determinant of choosing an alternative school. However, comparing magnet and charger schools, we see a very different pattern. Among magnet schools, it appears that value added gains in math impact own gains almost one-for-one. There is a similar but insignificant impact for reading, and a small and insignificant impact on writing scores. In contrast, the charter school, which has a reputation for improving math skills that may drive student selection, has a positive and significant coefficient on value added gain in math of 4.244, which is statistically different from 1 with a p-value of 0.046. In addition, moving from a home to charter school with the same value added in math implies a negative and significant loss in 
math scores. In fact, students only gain from charter entry if the value added of their home school is at least $0.21(0.911 / 4.244)$ lower than the value added of the charter. These coefficients suggest that selection on unobservables makes measuring the average treatment effect of the charter on math difficult. This is consistent with the observation that math program at the charter has a strong reputation amongst local students; it is possible that this reputation drives student selection. For the charter school, all students gain in writing, suggesting selection on positive gains in writing, but those gains are unrelated to the quality gap between the charter and the home school.

In sum, we find substantial gains in test scores for students choosing charter schools in this district, and evidence of gains among students choosing magnet schools though the estimates are noisier in part due to large differential attrition. Overall, test score increases for students choosing magnet programs are consistent with measures in increased value added between the choice and home school. However, selection into charter schools appears to be driven to a greater extent by unobservable student characteristics. Since charters are allowed to highly specialize and may attract students of parents looking for specialized schools to meet what they believe are their children's idiosyncratic needs, lottery estimates of local average treatment effects may be very different than what an average student might expect to gain if randomly assigned to that school. Magnet schools may not be so highly targeted or specialized, and particularly in the context of a broad magnet choice program where a large fraction of public schools are magnet choice schools.

\section{Conclusions}

We provide evidence that school choice has important impacts on motivation and test score performance for low-SES students using data from a mid-size urban school district. We find that winning the lottery to attend a chosen school has an immediate impact on absences and suspensions after notification, and that this result is particularly strong for older male students. We interpret this as students exerting more effort towards academics at their current school due to an increase in intrinsic motivation from knowing that they will be able to attend a school of their choice in the subsequent school year. To our knowledge, this is the first paper to separately 
identify this important channel through which NCLB school choice provisions may positively affect academic achievement among low-income and minority students.

In addition, we find evidence that attending the chosen school has a large and significant impact on student test scores particularly for the charter school in our sample. The lottery-based estimates of the effects of magnet school attendance are consistent with the predictions of a simple model in which the gains from attending the chosen school are equal to the difference between the chosen school and default school effects identified in an OLS value-added model. Lottery-based estimates of the effects of attending a charter school are not consistent with these predictions. For charters, heterogeneous effects and selection appear to play a stronger role; we find that selection into charter schools is more closely tied to unobservable test score determinants than selection into magnet schools. Overall, we add to the growing evidence that shows that schools and school choice can have important impacts on student achievement, particularly for students coming from persistently under-performing inner-city schools. 


\section{References:}

Angrist, Joshua D., Eric Bettinger, and Michael Kremer. (2006). "Long-Term Educational Consequences of Secondary School Vouchers: Evidence from Administrative Records in Colombia." American Economic Review. 96(3): 847-862.

Angrist, Joshua D., Susan M. Dynarski, Thomas J. Kane, Parag A. Pathak, and Christopher R. Walters. (2011) “Who Benefits from KIPP?” IZA Discussion Paper No. 5690.

Barsky, Robert B., John Bound, Kerwin Kofi Charles, and Joseph P.Lupton. (2002).

"Accounting for the Black-White Wealth Gap: A Nonparametric Approach." Journal of the American Statistical Association. 97: 663-673.

Bertrand, Marianne, Esther Duflo, and Sendhil Mullainathan. (2004). "How Much Should We Trust Differences-in-Differences Estimates?" Quarterly Journal of Economics. 119(1): 249-275.

Deming, David J., Justine S. Hastings, Thomas J. Kane, and Douglas O. Staiger. (2011). ““'School Choice and College Attendance: Evidence from Randomized Lotteries.” NBER Working Paper No. 17438.

Cullen, Julie Berry, Brian A. Jacob, and Steven Levitt. (2006). "The Effect of School Choice on Participants: Evidence from Randomized Lotteries.” Econometrica. 74(5): 1191-1230.

Cullen, Julie Berry, and Brian A. Jacob. (2008). "Is Gaining Access to a Selective Elementary School Gaining Ground? Evidence from Randomized Lotteries.” In Jonathan Gruber, ed. An Economics Perspective on the Problems of Disadvantaged Youth. Chicago, IL: University of Chicago Press.

Hastings, Justine S., Thomas J. Kane, Douglas O. Staiger, and Jeffrey M. Weinstein. (2007). "The Effect of Randomized School Admissions on Voter Participation." Journal of Public Economics. 91(5-6): 915-937. 
Hastings, Justine S., Thomas J. Kane, and Douglas O. Staiger. (2006, 2008). "Heterogeneous Preferences and the Efficacy of Public School Choice.” NBER Working Paper No. 12145. Hastings, Justine S., and Jeffrey M. Weinstein. (2008). “Information, School Choice and Academic Achievement: Evidence from Two Experiments.” Quarterly Journal of Economics. 123(4): 1373-1414.

Heckman, James J., Jora Stixrud, and Sergio Urzua. (2006). "The Effects of Cognitive and Noncognitive Abilities on Labor Market Outcomes and Social Behavior." Journal of Labor Economics. 24(3): 411-482.

Hirano, Keisuke., Guido Imbens, and Geert Ridder. (2003). "Efficient Estimation of Average Treatment Effects using the Estimated Propensity Score." Econometrica. 71(4): 1161-1189.

Hoxby, Caroline M., and Sonali Murarka. (2009). "Charter Schools in New York City: Who Enrolls and How They Affect Their Students’ Achievement.” NBER Working Paper No. 14852.

Imbens, Guido. (2004). "Nonparametric Estimation of Average Treatment Effects Under Exogeneity: A Review." Review of Economics and Statistics. 86(1): 4-29.

Lee, David S. (2009). "Training Wages, and Sample Selection: Estimating Sharp Bounds on Treatment Effects." Review of Economic Studies, 76(3): 1071-1102. 
TABLE 1: DESCRIPTIVE STATISTICS

\begin{tabular}{|c|c|c|c|c|c|c|c|c|c|c|c|c|}
\hline & $\begin{array}{c}\text { Distinct } \\
\text { Schools } \\
\text { in } 4 \\
\text { Years }^{1}\end{array}$ & $\begin{array}{l}\text { Student- } \\
\text { Years }\end{array}$ & $\begin{array}{c}\text { Percent } \\
\text { Black }\end{array}$ & $\begin{array}{c}\text { Percent } \\
\text { Hispanic }\end{array}$ & $\begin{array}{c}\text { Percent } \\
\text { White }\end{array}$ & $\begin{array}{l}\text { Percent } \\
\text { Female }\end{array}$ & $\begin{array}{c}\text { Percent } \\
\text { Not } \\
\text { F/R } \\
\text { Lunch }^{2}\end{array}$ & $\begin{array}{c}\text { Percent } \\
\text { with at } \\
\text { Least } 5 \\
\text { Absences }^{3}\end{array}$ & $\begin{array}{l}\text { Percent with } \\
\text { at least } 1 \\
\text { Suspension }^{4}\end{array}$ & $\begin{array}{l}\text { Percent } \\
\text { Proficient } \\
\text { in Math }\end{array}$ & $\begin{array}{l}\text { Percent } \\
\text { Proficient } \\
\text { Reading }\end{array}$ & $\begin{array}{l}\text { Percent } \\
\text { Proficient } \\
\text { Writing }\end{array}$ \\
\hline \multicolumn{13}{|l|}{ Preschool } \\
\hline Magnet & 15 & 1,311 & 42.3 & 31.3 & 24.0 & 48.0 & 15.6 & 75.8 & 0.2 & - & - & - \\
\hline Zoned & 24 & 6,175 & 51.4 & 41.0 & 6.0 & 48.8 & 2.1 & 60.6 & 0.0 & - & - & - \\
\hline \multicolumn{13}{|l|}{ Elementary $^{5}$} \\
\hline Charter & 2 & 1,384 & 72.3 & 24.9 & 2.5 & 48.1 & 5.5 & - & - & 88.0 & 62.9 & 89.7 \\
\hline Magnet & 13 & 14,707 & 53.1 & 33.6 & 11.4 & 48.9 & 7.9 & 69.1 & 6.9 & 67.7 & 44.6 & 69.7 \\
\hline Zoned & 22 & 18,653 & 44.7 & 43.1 & 9.9 & 48.6 & 5.8 & 74.4 & 6.9 & 57.9 & 33.4 & 57.3 \\
\hline \multicolumn{13}{|l|}{$\underline{\text { Middle }^{6}}$} \\
\hline Charter & 2 & 1,805 & 72.7 & 25.4 & 1.4 & 48.1 & 28.8 & - & - & 86.7 & 69.2 & 88.8 \\
\hline Magnet & 16 & 11,411 & 54.1 & 30.1 & 14.3 & 50.5 & 9.0 & 69.9 & 20.3 & 67.4 & 56.9 & 70.3 \\
\hline Zoned & 17 & 11,709 & 46.2 & 43.4 & 8.9 & 47.3 & 5.3 & 75.2 & 23.5 & 56.2 & 45.0 & 57.2 \\
\hline \multicolumn{13}{|l|}{ High $^{7}$} \\
\hline Charter & 1 & 70 & 58.6 & 41.4 & 0.0 & 57.1 & 30.0 & - & - & 83.1 & 95.3 & 100.0 \\
\hline Magnet & 11 & 21,346 & 54.6 & 27.8 & 16.1 & 51.8 & 7.1 & 80.5 & 18.1 & 47.9 & 60.8 & 68.2 \\
\hline Zoned & 4 & 1,478 & 57.8 & 38.4 & 3.4 & 39.3 & 1.8 & 81.2 & 34.9 & 25.4 & 39.2 & 55.7 \\
\hline
\end{tabular}

Note: Observations are at the student-year level over 4 years of data (2005-2006 through 2008-2009). Students who attrited and those in the seven transitional and special education

programs are not included. Students at the District's smallest charter school, which is not part of a national chain, are not included. ${ }^{1}$ Number of different schools that served a given grade level over the 4-year period. ${ }^{2}$ Students recorded as having sent in forms reporting that they do not qualify for free or reduced lunch. ${ }^{3}$ Students with at least 5 recorded absences, excused or unexcused, over the course of the school year. ${ }^{4}$ Students with at least 1 suspension in the school year. Data on absences and suspensions is not available for charter students. ${ }^{5}$ Grades K-4.

${ }^{6}$ Grades 5-8. ${ }^{7}$ Grades 9-12. 
TABLE 2: DESCRIPTIVE STATISTICS

\begin{tabular}{|c|c|c|c|c|c|c|c|c|c|c|c|c|c|c|}
\hline & \multicolumn{2}{|c|}{ Pre-K ${ }^{1}$} & \multicolumn{2}{|c|}{ Kinder-garten } & \multicolumn{2}{|c|}{ Grades 1-4 } & \multicolumn{2}{|c|}{ Grade 5} & \multicolumn{2}{|c|}{ Grade 6-8 } & \multicolumn{2}{|c|}{ Grade 9} & \multicolumn{2}{|c|}{ Grade 10-12 } \\
\hline $\begin{array}{l}\text { Lottery? } \\
\end{array}$ & No & Yes & No & Yes & No & Yes & No & Yes & No & Yes & No & Yes & No & Yes \\
\hline \multicolumn{15}{|l|}{ Demographics } \\
\hline Percent Black & 49.5 & 53 & 44.8 & 52.1 & 48.7 & 61.7 & 49.2 & 60 & 51.7 & 58.1 & 52.2 & 56.4 & 56.4 & 69.2 \\
\hline Percent Hispanic & 40.9 & 29.1 & 39.9 & 36 & 39.1 & 29.5 & 38.3 & 28.4 & 36.3 & 28.7 & 34.9 & 29.6 & 26.9 & 19.5 \\
\hline Percent White & 7.9 & 15.5 & 12.4 & 9.9 & 10.2 & 7.2 & 10.8 & 10.1 & 10.7 & 11.9 & 11.8 & 13 & 15.2 & 10.7 \\
\hline Percent Female & 48.4 & 50 & 48.3 & 48.8 & 48.8 & 47.2 & 47.4 & 50.8 & 48.3 & 48.3 & 40.1 & 56 & 51.5 & 52 \\
\hline $\begin{array}{l}\text { Percent Not F/R } \\
\text { Lunch }^{2}\end{array}$ & 3.1 & 14.1 & 6.2 & 9.5 & 6.3 & 7.5 & 7.4 & 14.4 & 8.1 & 10.1 & 3.6 & 7.7 & 6.5 & 8.2 \\
\hline N Student-years & 6,594 & 1,224 & 4,711 & 2,880 & 24,683 & 3,111 & 4,969 & 1,483 & 17,570 & 1,891 & 4,598 & 4,291 & 16,594 & 798 \\
\hline \multicolumn{15}{|c|}{$\begin{array}{l}\text { Academic Achievement } \\
\text { Mean Baseline }\end{array}$} \\
\hline $\begin{array}{l}\text { Math }^{3} \\
\text { Mean Baseline }\end{array}$ & -- & -- & -- & -- & -0.563 & -0.49 & -0.595 & -0.531 & -0.63 & -0.658 & -0.973 & -0.567 & -0.802 & -0.903 \\
\hline $\begin{array}{l}\text { Reading } \\
\text { Mean Baseline }\end{array}$ & -- & -- & -- & -- & -0.77 & -0.632 & -0.738 & -0.653 & -0.659 & -0.671 & -0.916 & -0.567 & -0.624 & -0.737 \\
\hline $\begin{array}{l}\text { Writing } \\
\text { N (All Baseline }\end{array}$ & -- & -- & -- & -- & -0.647 & -0.579 & -0.652 & -0.614 & -0.584 & -0.635 & -0.901 & -0.582 & -0.586 & -0.656 \\
\hline Scores $^{4}$ ) & -- & -- & -- & -- & 3,927 & 360 & 3,183 & 810 & 11,005 & 902 & 1,304 & 2,484 & 3,668 & 127 \\
\hline
\end{tabular}

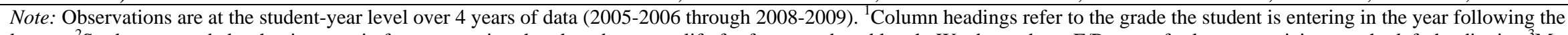

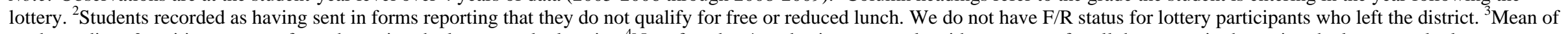
math, reading, \& writing z-scores from the spring the lottery took place in. ${ }^{4}$ No. of student*yr obs. in our sample with test scores for all three tests in the spring the lottery took place. 
TABLE 3: IMPACT OF WINNING THE LOTTERY ON

BASELINE CHARACTERISTICS

Coefficients are from the Regression of the

Following on an Indicator for Winning our

Simulated Lottery:

(1)

$\begin{array}{ccc}0.441^{* *} & 0.542 * * & 0.555 * * \\ (0.012) & (0.015) & (0.019) \\ 0.009 & 0.010 & 0.024 \\ (0.014) & (0.018) & (0.023) \\ -0.008 & -0.022 & -0.033 \\ (0.013) & (0.017) & (0.023) \\ 0.001 & 0.016 & 0.011 \\ (0.008) & (0.009) & (0.011) \\ 0.025 & 0.026 & 0.009 \\ (0.015) & (0.018) & (0.022) \\ & & 0.058\end{array}$

Baseline Math Z-Score

$(0.037)$

0.052

Baseline Reading Z-Score

(0.037)

0.018

Baseline Writing Z-Score

(0.034)

$\mathrm{P}$-value from joint $\mathrm{F}$-test

0.456

0.121

0.426

Observations

7,863

3,377

1,964

Note: Standard errors in parentheses; ** Significant at 1\%, * Significant at 5\%. Lottery block fixed effects included in all specifications. Sample is limited to marginal lottery students who chose a magnet (other than the one which is a transitional school) or charter (other than the District's smallest charter) as their first choice school. Students who did not have a normal grade progression are dropped. (1) All marginal students. (2) Marginal students in lotteries with good first stages and in grades 3-10. (3) Marginal students in lotteries with good first stages, in grades 3-10, and with all three baseline test scores. 
TABLE 4: IMPACT OF WINNING A LOTTERY ON TRUANCIES IN THE MONTHS FOLLOWING ADMISSION NOTIFICATION

\begin{tabular}{lcccccccccc}
\hline & \multicolumn{3}{c}{ Male and female students } & \multicolumn{3}{c}{ Male only } & \multicolumn{3}{c}{ Female only } \\
& All Grades & Grade 4+ & Grade 7+ & All Grades & Grade 4+ & Grade 7+ & All Grades & Grade 4+ & Grade 7+ \\
\hline \multirow{3}{*}{ Won lottery X Post } & & & & & & & & & \\
& $-0.019^{*}$ & $-0.023^{*}$ & -0.023 & $-0.038^{* *}$ & $-0.053^{* *}$ & $-0.063^{* *}$ & -0.002 & 0.002 & 0.008 \\
Post & $(0.009)$ & $(0.011)$ & $(0.013)$ & $(0.014)$ & $(0.017)$ & $(0.021)$ & $(0.012)$ & $(0.014)$ & $(0.016)$ \\
& $0.062^{* *}$ & $0.065^{* *}$ & $0.063^{* *}$ & $0.065^{* *}$ & $0.074^{* *}$ & $0.079^{* *}$ & $0.060^{* *}$ & $0.057^{* *}$ & $0.049^{* *}$ \\
& $(0.006)$ & $(0.007)$ & $(0.009)$ & $(0.009)$ & $(0.011)$ & $(0.014)$ & $(0.008)$ & $(0.010)$ & $(0.011)$ \\
Observations & & & & & & & & \\
R-squared & 4,293 & 2,870 & 2,215 & 2,059 & 1,312 & 982 & 2,234 & 1,558 & 1,233 \\
Mean Weekly Truancies & 0.001 & 0.002 & 0.001 & 0.004 & 0.008 & 0.009 & 0.000 & 0.000 & 0.000 \\
\hline
\end{tabular}

Note: Standard errors in parentheses; ** Significant at 1\%, * Significant at 5\%. Sample is limited to marginal lottery students who chose a magnet (other than the one transitional magnet) or charter (other than the District's smallest charter) as their first choice school. Students without a normal grade progression in the year following the lottery are dropped. The dependent variable is mean weekly truancies. Estimated using first differences with observations at the student-year level. 
TABLE 5: IMPACT OF WINNING A LOTTERY ON TRUANCIES IN THE MONTHS FOLLOWING ADMISSION NOTIFICATION

\begin{tabular}{|c|c|c|c|c|c|c|c|c|c|}
\hline & \multicolumn{3}{|c|}{ Male and female students } & \multicolumn{3}{|c|}{ Male only } & \multicolumn{3}{|c|}{ Female only } \\
\hline & All Grades & Grade 4+ & Grade 7+ & All Grades & Grade 4+ & Grade 7+ & All Grades & Grade 4+ & Grade 7+ \\
\hline \multirow{2}{*}{ Lost lottery X Post } & -0.007 & -0.011 & -0.017 & -0.004 & -0.006 & -0.003 & -0.009 & -0.016 & -0.028 \\
\hline & $(0.008)$ & $(0.010)$ & $(0.012)$ & $(0.011)$ & $(0.015)$ & $(0.019)$ & $(0.011)$ & $(0.014)$ & $(0.017)$ \\
\hline \multirow[t]{2}{*}{ Won lottery X Post } & $-0.026 * *$ & $-0.034 * *$ & $-0.040 * *$ & $-0.042 * *$ & $-0.059 * *$ & $-0.066 * *$ & -0.011 & -0.014 & -0.020 \\
\hline & $(0.008)$ & $(0.010)$ & $(0.012)$ & $(0.011)$ & $(0.013)$ & $(0.017)$ & $(0.011)$ & $(0.014)$ & $(0.017)$ \\
\hline \multirow[t]{2}{*}{ Post } & $0.069 * *$ & $0.076^{* *}$ & $0.079 * *$ & $0.069 * *$ & $0.080^{* *}$ & $0.082^{* *}$ & $0.068^{* *}$ & $0.073^{* *}$ & $0.077 * *$ \\
\hline & $(0.005)$ & $(0.006)$ & $(0.008)$ & $(0.006)$ & $(0.008)$ & $(0.010)$ & $(0.007)$ & $(0.010)$ & $(0.012)$ \\
\hline Observations & 37,035 & 18,524 & 10,423 & 19,205 & 9,609 & 5,496 & 17,830 & 8,915 & 4,927 \\
\hline R-squared & 0.001 & 0.002 & 0.002 & 0.003 & 0.005 & 0.006 & 0.000 & 0.001 & 0.001 \\
\hline Mean Weekly Truancies & 0.342 & 0.379 & 0.439 & 0.346 & 0.384 & 0.443 & 0.338 & 0.374 & 0.435 \\
\hline $\mathrm{P}$ Value t-test & 0.034 & 0.033 & 0.070 & 0.005 & 0.001 & 0.002 & 0.856 & 0.886 & 0.623 \\
\hline
\end{tabular}


TABLE 6: ITT EFFECTS OF WINNING A SCHOOL CHOICE LOTTERY

\begin{tabular}{|c|c|c|}
\hline Intent to Treat & $(1)$ & $(2)$ \\
\hline \multicolumn{3}{|l|}{ Panel I } \\
\hline First Choice Attendance & $\begin{array}{c}0.587 * * \\
(0.020)\end{array}$ & $\begin{array}{c}0.609 * * \\
(0.027)\end{array}$ \\
\hline Mean First Choice Attendance & 0.484 & 0.470 \\
\hline Observations & 1,799 & 959 \\
\hline \multicolumn{3}{|l|}{ Panel II } \\
\hline Attrition from district & $\begin{array}{c}-0.093 * * \\
(0.013)\end{array}$ & $\begin{array}{c}-0.079 * * \\
(0.023)\end{array}$ \\
\hline Baseline score & & $\begin{array}{c}0.013 \\
(0.016)\end{array}$ \\
\hline Baseline score*won lottery & & $\begin{array}{l}-0.006 \\
(0.024)\end{array}$ \\
\hline Mean Attrition & 0.121 & 0.105 \\
\hline Observations & 2,780 & 1,436 \\
\hline \multicolumn{3}{|l|}{ Panel III } \\
\hline Attrition from full score sample & $\begin{array}{c}-0.144^{* *} \\
(0.019)\end{array}$ & $\begin{array}{c}-0.104^{* *} \\
(0.033)\end{array}$ \\
\hline Baseline score & & $\begin{array}{c}-0.137^{* *} \\
(0.023)\end{array}$ \\
\hline Baseline score*won lottery & & $\begin{array}{c}0.026 \\
(0.035)\end{array}$ \\
\hline Mean score attrition & 0.353 & 0.334 \\
\hline Observations & 2,780 & 1,436 \\
\hline \multicolumn{3}{|l|}{ Panel IV } \\
\hline Pooled Combined Z-Score & $\begin{array}{l}0.111 * * \\
(0.0349)\end{array}$ & $\begin{array}{c}0.161 * * \\
(0.0263)\end{array}$ \\
\hline Observations & 1,799 & 957 \\
\hline Magnet School Combined Z-Score & $\begin{array}{c}0.063 \\
(0.0387)\end{array}$ & $\begin{array}{c}0.124 * * \\
(0.0304)\end{array}$ \\
\hline Observations & 1325 & 698 \\
\hline Charter Combined Z-Score & $\begin{array}{c}0.260 * * \\
(0.0765)\end{array}$ & $\begin{array}{c}0.244 * * \\
(0.0506)\end{array}$ \\
\hline Observations & 474 & 259 \\
\hline
\end{tabular}

Note: Standard errors in parentheses; ${ }^{* *}$ Significant at $1 \%$, * Significant at $5 \%$. Lottery block fixed effects included in all specifications. Coefficients are from regressions of outcome variables on an indicator for winning our simulated lottery. Sample is limited to marginal lottery students who chose a magnet (other than the one transitional magnet) or charter (other than the District's smallest charter) as their first choice school. Students who did not have a normal grade progression are dropped. Students in lottery blocks where the first stage coefficient is $<.2$ are dropped. Outcome z-score for students entering 9th grade is their score from 10th grade as 9th graders do not take state tests. (1) Sample is all marginal students with all three outcome test scores (all three 10th grade scores for 9th graders); sample for the attrition regression is all students in lotteries which include students with outcome scores (2) Baseline test scores for each subject are included in these specifications. Sample is marginal students with baseline and outcome test scores in all three subjects; sample for the attrition regression is all students in lotteries which include students with outcome scores. 
TABLE 7: IV ESTIMATES OF EFFECTS OF FIRST CHOICE ATTENDANCE BY SUBJECT AND SCHOOL TYPE

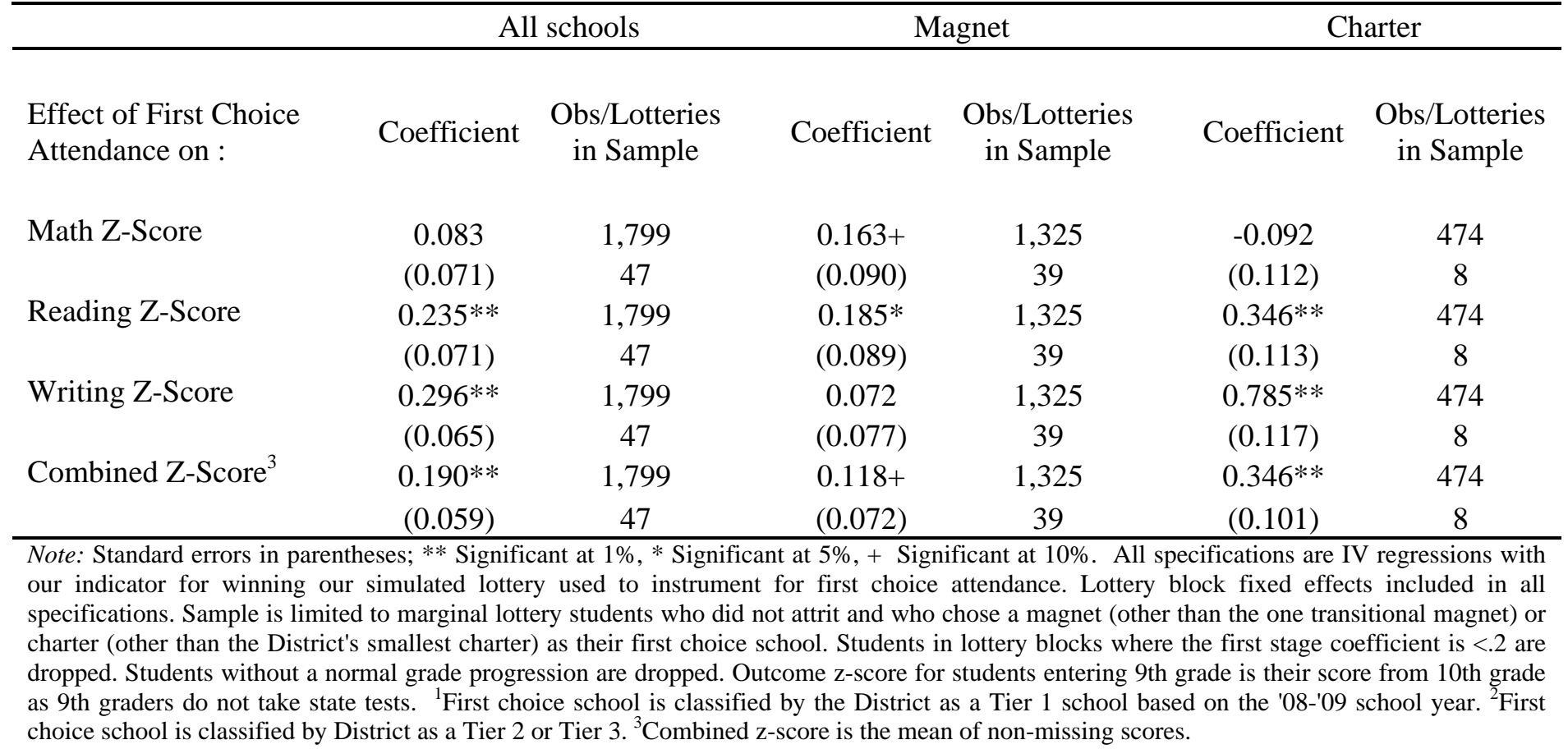


TABLE 8: DIFFERENCES IN AVERAGE VALUE ADDED GAIN FOR LOTTERY

\begin{tabular}{llccccc}
\hline & FC type & Home $^{1}$ & FC $^{2}$ & Gap $^{3}$ & Gap SD & N \\
\hline Combined & & & & & & \\
& Magnet & -0.189 & -0.022 & 0.164 & 0.098 & 1,197 \\
& Charter & -0.012 & 0.169 & 0.181 & 0.052 & 459 \\
& Total & -0.14 & 0.028 & 0.169 & 0.088 & 1,656 \\
& & & & & & 0.155 \\
Math score & Magnet & -0.329 & -0.142 & 0.178 & 0.066 & 459 \\
& Charter & -0.004 & 0.188 & 0.192 & 0.137 & 1,656 \\
& Total & -0.239 & -0.055 & 0.182 & & \\
\hline Reading & & & & & & \\
score & Magnet & -0.197 & -0.028 & 0.167 & 0.123 & 1,197 \\
& Charter & -0.003 & 0.112 & 0.115 & 0.061 & 459 \\
& Total & -0.143 & 0.009 & 0.153 & 0.112 & 1,656 \\
& & & & & & \\
\hline Writing & & & & & & \\
score & Magnet & -0.039 & 0.131 & 0.172 & 0.118 & 1,197 \\
& Charter & -0.046 & 0.329 & 0.375 & 0.08 & 459 \\
& Total & -0.041 & 0.183 & 0.228 & 0.142 & 1,656 \\
\hline
\end{tabular}

Note: Descriptive statistics for value added estimates of zoned schools and target schools. ${ }^{1}$ Mean value added of zoned school. ${ }^{2}$ Mean value added of chosen or target school in lottery. ${ }^{3}$ Mean gap between zone and target value added ${ }^{4}$ SD of gap between zoned and target value added. Sample includes all students in marginal lotteries. 
TABLE 9: IV ESTIMATES OF THE IMPACT OF SCHOOL VALUE-ADDED

MEASURES ON STUDENT OUTCOMES

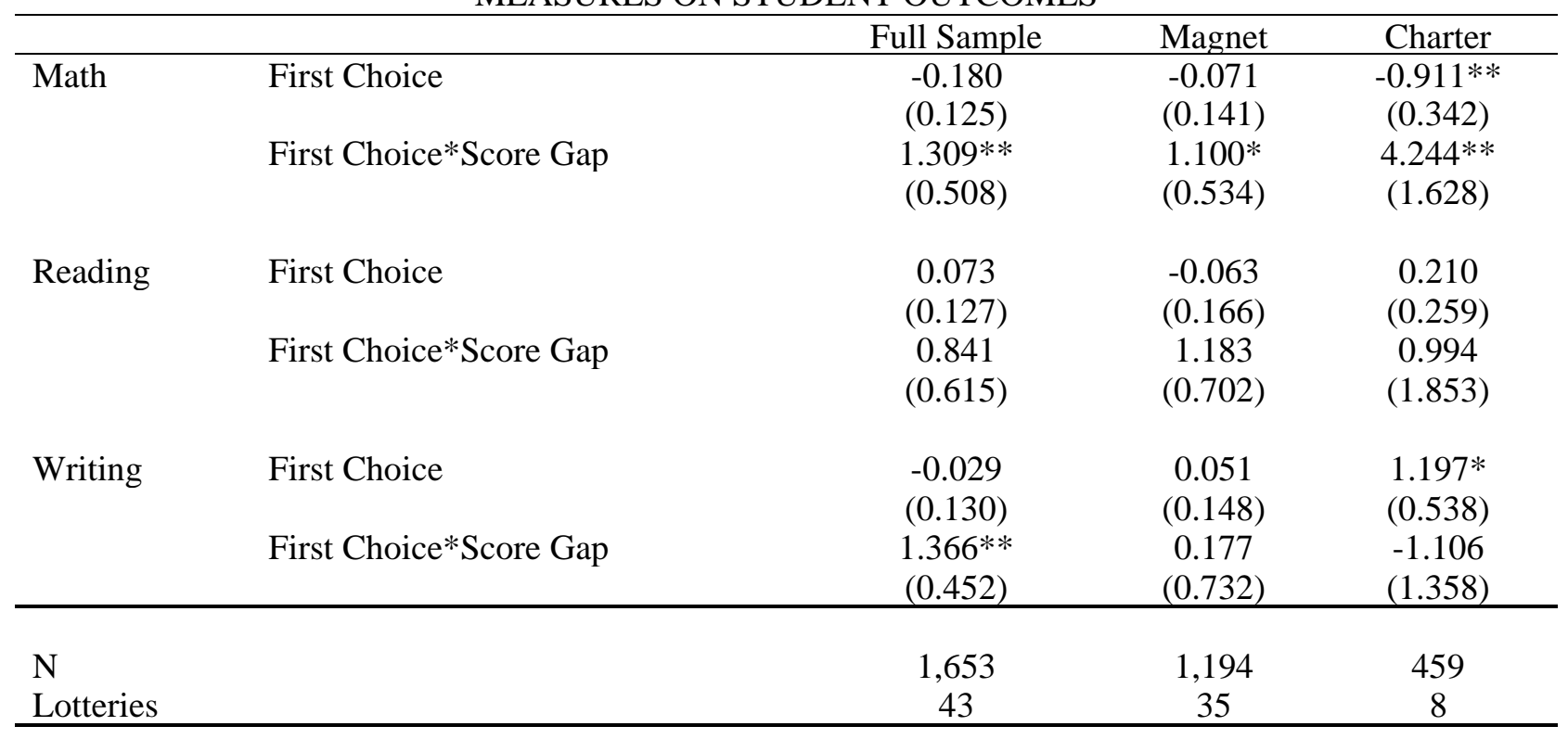

Note: Standard errors in parentheses; ** Significant at 1\%, * Significant at 5\%. All specifications are IV regressions. The instruments are simulated lottery outcome and simulated lottery outcome interacted with the VA gap between the first choice school and the zoned school. Lottery block fixed effects and zone school fixed effects included in all specifications. Sample is limited to marginal lottery students who did not attrit and who chose a magnet (other than the one transitional magnet) or charter (other than the District's smallest charter) as their first choice school. Students in lottery blocks where the first stage coefficient is $<.2$ are dropped. Students without a normal grade progression are dropped. 


\section{APPENDIX A: SAMPLE CONSTRUCTION AND LOTTERY INSTRUMENT FIT}

This appendix describes the procedure we use to construct the simulated lottery outcome variable. If lottery results are fully determined by a random rank ordering, implementing our identification strategy only requires data on lottery numbers, priority groups, and the number of seats allocated for each grade and school choice. The data from the district contain the chosen schools, the student's priority groups (for each choice), as well as their lottery number and their home school. However, instead of recording if students were admitted based on lottery number, the data record whether the student was eventually admitted by the subsequent fall. This includes, for example, the many admissions that are made off of the first-choice waitlists as families move or change their plans, or schools readjust their available seat limit between March and August. ${ }^{14}$

Thus, we reconstruct the original lottery-based admissions using the lottery numbers, choices, priorities and available seats at the time the lottery was run. We generate an indicator for winning the lottery if the student's lottery number was less than the cut-off number of seats available for that school and choice at the time the lottery was run. Concretely, if school choice $C$ had a total number of spots $S$ allocated to within-district admission, for example, we assign the student with the $m$ th lowest lottery number and priority group an admission if $m \leq S$.

For most lotteries, lottery-based admissions are positively correlated with the actual admissions as of the subsequent fall when the annual school choice file is closed out. However, for many of the small lotteries, the simulated admission indicator is only weakly positively correlated with actual admissions. To assess the strength of the relationship between simulated and observed lottery outcomes, we estimate the equation

$$
A_{i}=\delta_{0}+\delta_{1} L_{i}+e_{i}
$$

\footnotetext{
${ }^{14}$ While waitlist rank is determined by lottery number, when a slot becomes available, parents are contacted in sequence until a parent is reached and takes the slot. Thus lottery number alone does not determine wait-list admission.
} 
separately for each lottery. Here, $A_{i}$ is an indicator variable equal to one if a student was admitted to the chosen school by the fall, while $L_{i}$ is an indicator equal to one if the student was a lottery winner. The parameter of interest is $\delta_{1}$, which measures how much more likely simulated lottery winners were to gain actual admission than were simulated lottery losers.

Figure A1 and the first panel of Table A1 report summary statistics for $\delta_{1}$ weighted by the number of student-level observations, while Figure A2 and the second panel of Table A1 report the same statistics weighted by number of lotteries. Figure 1 shows that there is substantial heterogeneity in the extent to which eventual admissions conform to the lottery-only results. However, the median student was 35.3 percentage points more likely to win the lottery if she had a low enough lottery and priority number, and 25 percent of students participated in lotteries where having a low enough lottery and priority number implied a 66.4 percentage-point boost in probability of admission. Charter school lotteries conformed more closely simulated results: on average, winning the lottery increased the chance of being admitted by the fall by 45.9 percentage points, with 25 percent of students in lotteries where the simulated outcome raised the probability of winning by at least 74.2 percentage points. In magnet school lotteries, the mean boost from in selection probability from simulated victory was 31.2 percent, with the top quartile of students experiencing at least a 60 percent gain.

Comparing Figure A1 to Figure A2, we see that weighting results by lottery rather than student pushes the distribution of estimates downward. This is because lotteries in which the simulated lottery outcome has a weak relationship with observed lottery outcome generally have few participants. For these small lotteries, projected available seats and student mobility may add noise to the process, attenuating the correlation between lottery admissions and eventual admissions. $^{15}$

Lotteries in which simulated lottery outcome has a very weak relationship with reported lottery outcome likely admitted many students through the potentially endogenous waitlist process. We

\footnotetext{
${ }^{15}$ In particular, seat projections are made prior to March for the coming year. Principles use projections of how many students may be held back to forecast additional available seats. Thus, the projections are typically conservative as there is no overflow space should too many students be admitted. This projection process causes some lotteries, and particularly those for small classes to admit most students off of the waitlist rather than off of original lottery number.
} 
do not want to include these in our sample. For our analysis, we drop all lotteries in which $\delta_{1}$ is less than 0.2. This reduces our sample size from 7,863 to 4,277. Our results are generally insensitive to changes in this cutoff value, though reducing the cutoff value raises our standard errors, particularly for estimates of magnet school effects. 

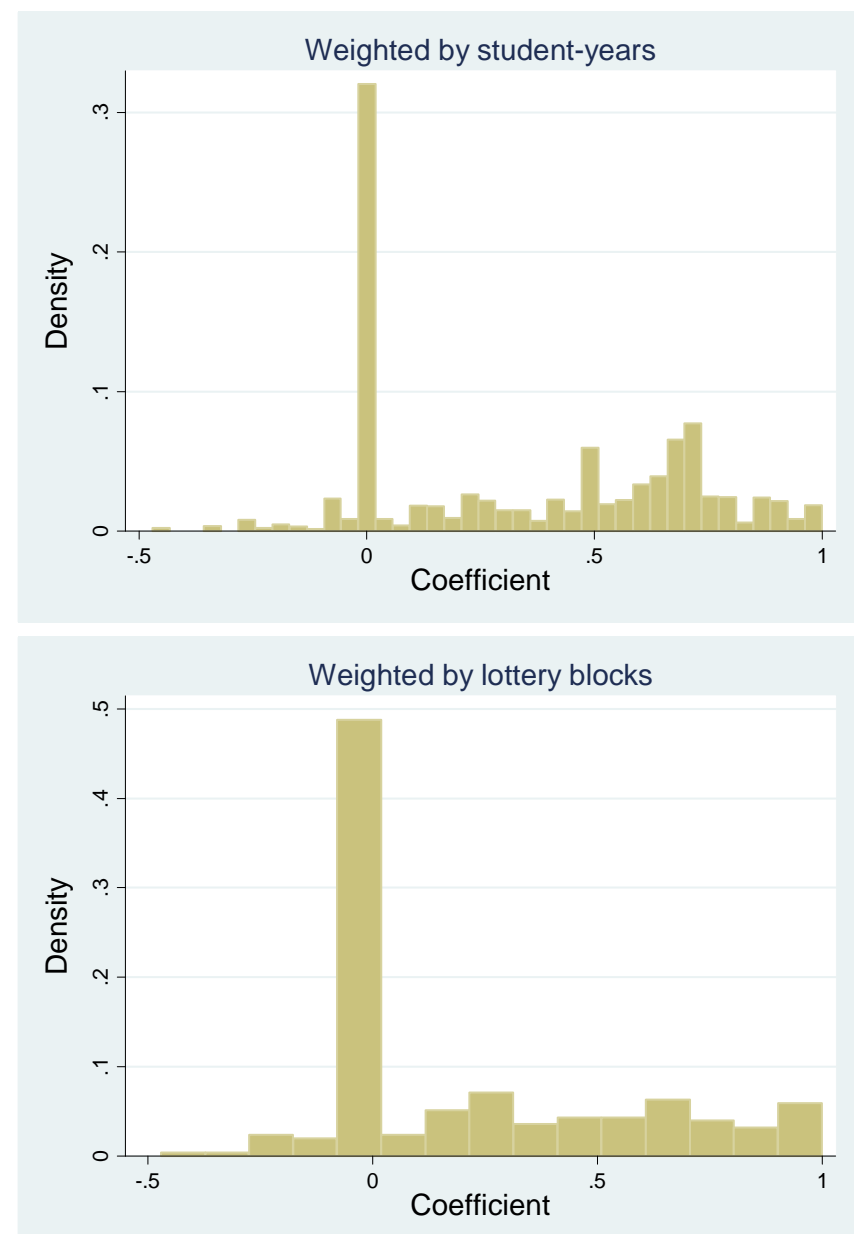

TABLE A1: CHARACTERISTICS OF LOTTERY INSTRUMENT FIT ACROSS LOTTERIES

\begin{tabular}{lccrr}
\hline & \multicolumn{4}{c}{ First Lottery Instrument Fit $^{1}$} \\
\cline { 2 - 5 } Marginal Lotteries $^{2}$ & Mean & $\begin{array}{c}\text { 25th } \\
\text { Percentile }\end{array}$ & $\begin{array}{c}\text { 50th } \\
\text { Percentile }\end{array}$ & $\begin{array}{c}\text { 75th } \\
\text { Percentile }\end{array}$ \\
\hline Weighted by N Students & & & \\
All Schools & 0.344 & 0 & 0.333 & 0.664 \\
Charter $^{3}$ & 0.459 & 0 & 0.647 & 0.742 \\
Magnet $^{4}$ & 0.312 & 0 & 0.267 & 0.6 \\
\hline Weighted by Lottery & & & & 0.5 \\
All Schools & 0.227 & 0 & 0 & 0.728 \\
Charter $^{3}$ & 0.315 & 0 & 0 & 0.444 \\
Magnet $^{4}$ & 0.213 & 0 & 0 & \\
\hline
\end{tabular}




\section{APPENDIX B: ADDRESSING THE IMPACT OF DIFFERENTIAL ATTRITION ON ITT ESTIMATES OF WINNING A SCHOOL CHOICE LOTTERY}

\begin{tabular}{|c|c|c|c|c|}
\hline \multirow[b]{2}{*}{ Pooled } & \multicolumn{2}{|c|}{ Pooled Sample } & \multicolumn{2}{|c|}{$\begin{array}{c}\text { Sample with } \\
\text { Baseline Scores }\end{array}$} \\
\hline & Estimate & $\mathrm{N}$ & Estimate & $\mathrm{N}$ \\
\hline Point & 0.111 & 1,799 & 0.160 & 959 \\
\hline Upper Bound & 0.316 & 1,602 & 0.280 & 874 \\
\hline Lower Bound & -0.094 & 1,602 & 0.041 & 875 \\
\hline Magnet & Estimate & $\mathrm{N}$ & Estimate & $\mathrm{N}$ \\
\hline Point & 0.063 & 1,325 & 0.132 & 700 \\
\hline Upper Bound & 0.295 & 1,159 & 0.269 & 629 \\
\hline Lower Bound & -0.173 & 1,159 & -0.014 & 630 \\
\hline Charter & Estimate & $\mathrm{N}$ & Estimate & $\mathrm{N}$ \\
\hline Point & 0.260 & 474 & 0.237 & 259 \\
\hline Upper Bound & 0.374 & 443 & 0.306 & 245 \\
\hline Lower Bound & 0.125 & 443 & 0.176 & 245 \\
\hline
\end{tabular}

Lee (2009) bounds computed separately within lotteries and averaged using entrant-level weights. The first column is for the pooled sample corresponding to column 1 estimates in Table 6. The second column estimates the impact among those with baseline test scores, using the difference between outcome and baseline test scores as the dependent variable. This column corresponds to the results in column 2 of Table 6. 